\title{
Early nasal high-flow versus Venturi mask oxygen therapy after lung resection: a randomized trial
}

\author{
Mariano Alberto Pennisi ${ }^{1,2}$, Giuseppe Bello ${ }^{1,2^{*}}$, Maria Teresa Congedo ${ }^{3,4}$, Luca Montini ${ }^{1,2}$, Dania Nachira ${ }^{3,4}$, \\ Gian Maria Ferretti ${ }^{3,4}$, Elisa Meacci ${ }^{3,4}$, Elisabetta Gualtieri ${ }^{1,2}$, Gennaro De Pascale ${ }^{1,2}$, Domenico Luca Grieco ${ }^{1,2}$, \\ Stefano Margaritora ${ }^{3,4}$ and Massimo Antonelli, ${ }^{1,2}$
}

\begin{abstract}
Background: Data on high-flow nasal oxygen after thoracic surgery are limited and confined to the comparison with low-flow oxygen. Different from low-flow oxygen, Venturi masks provide higher gas flow at a predetermined fraction of inspired oxygen $\left(\mathrm{FiO}_{2}\right)$. We conducted a randomized trial to determine whether preemptive high-flow nasal oxygen reduces the incidence of postoperative hypoxemia after lung resection, as compared to Venturi mask oxygen therapy.

Methods: In this single-center, randomized trial conducted in a teaching hospital in Italy, consecutive adult patients undergoing thoracotomic lung resection, who were not on long-term oxygen therapy, were randomly assigned to receive high-flow nasal or Venturi mask oxygen after extubation continuously for two postoperative days. The primary outcome was the incidence of postoperative hypoxemia (i.e., ratio of the partial pressure of arterial oxygen to $\mathrm{FiO}_{2}$ $\left(\mathrm{PaO}_{2} / \mathrm{FiO}_{2}\right)$ lower than $300 \mathrm{mmHg}$ ) within four postoperative days.

Results: Between September 2015 and April 2018, 96 patients were enrolled; 95 patients were analyzed (47 in high-flow group and 48 in Venturi mask group). In both groups, 38 patients (81\% in the high-flow group and $79 \%$ in the Venturi mask group) developed postoperative hypoxemia, with an unadjusted odds ratio (OR) for the high-flow group of 1.11 [95\% confidence interval (Cl) 0.41-3] ( $p=0.84$ ). No inter-group differences were found in the degree of dyspnea nor in the proportion of patients needing oxygen therapy after treatment discontinuation (OR 1.34 [95\% Cl 0.60-3]), experiencing pulmonary complications (OR 1.29 [95\% Cl 0.51-3.25]) or requiring ventilatory support (OR $0.67[95 \% \mathrm{Cl} 0.11-4.18]$ ). Post hoc analyses revealed that $\mathrm{PaO}_{2} / \mathrm{FiO}_{2}$ during the study was not different between groups $(p=0.92)$, but patients receiving high-flow nasal oxygen had lower arterial pressure of carbon dioxide, with a mean inter-group difference of $2 \mathrm{mmHg}$ [95\% Cl 0.5-3.4] ( $p=0.009)$, and were burdened by a lower risk of postoperative hypercapnia (adjusted OR 0.18 [95\% Cl 0.06-0.54], $p=0.002$ ).

Conclusions: When compared to Venturi mask after thoracotomic lung resection, preemptive high-flow nasal oxygen did not reduce the incidence of postoperative hypoxemia nor improved other analyzed outcomes. Further adequately powered investigations in this setting are warranted to establish whether high-flow nasal oxygen may yield clinical benefit on carbon dioxide clearance.

(Continued on next page)
\end{abstract}

\footnotetext{
* Correspondence: gsppbll@gmail.com

'Dipartimento delle Scienze dell'Emergenza, Anestesiologiche e della

Rianimazione, UOC di Anestesia, Rianimazione, Terapia Intensiva e

Tossicologia Clinica, Fondazione Policlinico Universitario A. Gemelli IRCCS,

Rome, Italy

${ }^{2}$ Istituto di Anestesia e Rianimazione, Università Cattolica del Sacro Cuore,

Rome, Italy

Full list of author information is available at the end of the article
}

(c) The Author(s). 2019 Open Access This article is distributed under the terms of the Creative Commons Attribution 4.0 International License (http://creativecommons.org/licenses/by/4.0/), which permits unrestricted use, distribution, and reproduction in any medium, provided you give appropriate credit to the original author(s) and the source, provide a link to the Creative Commons license, and indicate if changes were made. The Creative Commons Public Domain Dedication waiver (http://creativecommons.org/publicdomain/zero/1.0/) applies to the data made available in this article, unless otherwise stated. 
(Continued from previous page)

Trial registration: ClinicalTrials.gov, NCT02544477. Registered 9 September 2015.

Keywords: Hypoxemia, High-flow oxygen therapy, Noninvasive ventilation, Postoperative pulmonary complications, Thoracotomic lobectomy

\section{Background}

Patients undergoing lung resection are jeopardized by relevant postoperative morbidity and mortality [1-3]. Acute respiratory failure is the most common life-threatening complication after thoracic surgery. Supplemental oxygen is often needed to improve arterial oxygenation in the postoperative period: despite it is effective in treating most cases of hypoxemia, patients with low ventilation-perfusion ratio may be only partially responsive to an increase in oxygen concentration. Noninvasive ventilation (NIV) has been proposed to prevent/treat respiratory failure after lung resection [4-8], but its routine use in clinical practice requires personnel expertise and technological resources that may not be available in all post-anesthesia care units and surgical wards. In addition, in the early postoperative period, delivery of positive pressure in the airways and eventual patient-ventilator asynchronies during assisted ventilation may pose a risk to the tightness of bronchial anastomosis by means of uncontrolled swings in the transmural pressure of the airways.

The use of nasal cannula to deliver high flow rates of heated and humidified gas at a predetermined fraction of inspired oxygen $\left(\mathrm{FiO}_{2}\right)$ is an attractive alternative to conventional oxygen therapy and, possibly, to NIV [9]. The beneficial effects of high-flow nasal cannula (HFNC) include (a) delivery of high flows, that better match patients' peak inspiratory flow, finally enabling administration of set $\mathrm{FiO}_{2}$; (b) provision of a small degree of positive pressure in the airways, that increases end-expiratory lung volume; (c) washout of nasopharyngeal dead space, which enhances carbon dioxide $\left(\mathrm{CO}_{2}\right)$ removal; and (e) good tolerance and comfort [10-14]. HFNC, as compared to low-flow oxygen, prevents respiratory failure after extubation in the intensive care unit and is as effective as NIV after cardiothoracic surgery and in patients with difficult separation from mechanical ventilation [15-19]. Also when compared to oxygen therapy with Venturi mask, which itself produces mid-to-high flows of gas at predetermined $\mathrm{FiO}_{2}$ due to an air entrainment mechanism, HFNC improves oxygenation, comfort, and $\mathrm{CO}_{2}$ clearance, possibly facilitating weaning from mechanical ventilation in critically ill patients [20].

No study ever compared HFNC and Venturi mask for oxygen therapy after thoracic surgery: we hereby report the results of a randomized trial conducted to determine whether early treatment with HFNC, as compared to
Venturi mask, can prevent the development of clinically relevant hypoxemia after thoracotomic lung lobectomy.

\section{Methods \\ Study design}

This single-center, open-label, randomized controlled study was conducted in the post-anesthesia care unit, surgical intensive care unit, and thoracic surgical ward of a tertiary university hospital in Italy, between September 2015 and April 2018. The protocol was approved by the local ethics committee and was registered on Clinical Trials.gov (NCT02544477) before trial initiation. The study was conducted in accordance with the declaration of Helsinki, and written informed consent was obtained from all enrolled subjects according to committee recommendations.

\section{Participants}

All adult patients scheduled for elective thoracotomic pulmonary lobar resection for malignant disease were eligible for study inclusion. Exclusion criteria were refusal of informed consent, pregnancy, body mass index $\geq 35 \mathrm{~kg} / \mathrm{m}^{2}$, history of obstructive sleep apnea syndrome, long-term oxygen therapy due to chronic pulmonary disease, presence of tracheostomy, and any nasal/facial defect that could impede HFNC or Venturi mask use.

Patients enrolled in the study were randomized to receive oxygen therapy by a Venturi face mask or a treatment with HFNC continuously over the course of $48 \mathrm{~h}$ after surgery. A computer-generated random allocation list was used to allocate enrolled patients to study arms.

\section{Patient management during surgery}

All enrolled patients received general anesthesia according to the following standard protocols: induction with propofol 2-3 mg/kg, fentanyl $1.5-2.5 \mathrm{mcg} / \mathrm{kg}$, and rocuronium bromide $0.9 \mathrm{mg} / \mathrm{kg}$; maintenance provided by sevoflurane titrated to keep bi-spectral index values between 40 and $60 \%$, continuous infusion remifentanil 0.05-0.4 $\mathrm{mcg} / \mathrm{kg} / \mathrm{min}$, repeated boluses of rocuronium bromide $0.02 \mathrm{mg} \mathrm{kg}^{-1}$ to maintain a train of four of $1-3$ by neuromuscular monitoring, and $3-5 \mathrm{ml} / \mathrm{kg} / \mathrm{h}$ of intravenous crystalloids and antibiotic prophylaxis; and postoperative analgesia was obtained by intercostal nerve block at the end of the procedure and paracetamol at a standard dose for the first three postoperative days. 
During surgery, all patients were ventilated with a tidal volume of $6-8 \mathrm{ml} / \mathrm{kg}$ of predicted body weight [21] for two-lung ventilation and of $5 \mathrm{ml} / \mathrm{kg}$ for one-lung ventilation; PEEP was set at $5 \mathrm{cmH}_{2} \mathrm{O}$ throughout the whole surgical procedure. Recruitment maneuvers were performed once (i.e., after lobectomy) in all patients.

At the end of surgery, patients were extubated as the following criteria were met: spontaneous respiratory activity with exhaled tidal volume between 5 and $8 \mathrm{ml} / \mathrm{kg}$; respiratory frequency ranging between 12 and 30 breaths/min; absence of residual neuromuscular blockade, as assessed by train-of-four monitoring; peripheral oxygen saturation $\left(\mathrm{SpO}_{2}\right) \geq 92 \%$; hemodynamic stability (heart rate $<120 / \mathrm{min}$; systolic blood pressure between 90 and $160 \mathrm{mmHg}$; no signs of cardiac ischemia, no hemodynamically significant arrhythmias and absence of catecholamines); body temperature $\geq 36{ }^{\circ} \mathrm{C}$; adequate cough reflex; and absence of copious secretions.

After extubation, enrolled patients were transferred to either the post-anesthesia care unit or the intensive care unit, according to the decision of the attending anesthesiologist, who was not aware of the randomization arm. According to department guidelines, early intensive care unit admission was reserved to American Society of Anesthesiologists' three patients who were deemed at high-risk of postoperative complications. Patients treated in the post-anesthesia care unit were transferred to the surgical ward within 4-8 h after surgery, unless deemed clinically inappropriate. Patients treated in the intensive care unit were transferred to the surgical ward on postoperative day 1 , unless clinically contraindicated.

\section{Study treatments}

All patients had to undergo the assigned treatment within $30 \mathrm{~min}$ after extubation.

Patients in the control group received oxygen therapy via a Venturi mask (OS/60 K, FIAB, Florence, Italy); pure $\mathrm{O}_{2}$ flow was set depending on the needed $\mathrm{FiO}_{2}$ according to manufacturer recommendations. Patients in the intervention group received HFNC by AIRVO ${ }^{\text {mix }}$ (Fisher \& Paykel Healthcare Ltd., Auckland, New Zealand). The initial flow rate was $50 \mathrm{l} / \mathrm{min}$ and was eventually diminished in case of intolerance. Humidification chamber temperature was set at $37^{\circ} \mathrm{C}$ and eventually diminished in case of intolerance.

In both groups, $\mathrm{SpO}_{2}$ was monitored continuously and $\mathrm{FiO}_{2}$ was titrated on an hour basis to maintain $\mathrm{SpO}_{2}$ between $92 \%$ and $98 \%$. The assigned treatment was administered continuously until day 2 after surgery, 9.00 a.m., when patients were assessed for treatment interruption; study treatments were discontinued and patients were deemed weaned from oxygen therapy as the following criteria were met: respiratory rate $\leq 35$ breaths/min; no recruitment of accessory muscles during calm breathing; hemodynamic stability (heart rate $<120 / \mathrm{min}$; systolic blood pressure between 90 and $160 \mathrm{mmHg}$; no signs of cardiac ischemia, no hemodynamically significant arrhythmias, and absence of catecholamines); and core body temperature $<38.5^{\circ} \mathrm{C}$. After day 2, in case of failure to be weaned from oxygen therapy, all enrolled patients received Venturi Mask oxygen therapy, as long as deemed appropriate by the attending physician.

In the surgical ward, patients from both groups underwent a standard physiotherapy protocol: over the initial $24 \mathrm{~h}$, this consisted of upright positioning, sitting on the edge of the bed or on the chair, non-resistance leg exercises, and lung expansion maneuvers twice a day (i.e., deep diaphragmatic breathing, thoracic expansion exercises, and incentive spirometry). As soon as the patient was weaned from oxygen therapy, a walking program was also adopted.

\section{Measurements}

Baseline blood gas analysis was obtained in the preoperative period. Postoperative blood gas analyses and dyspnea assessment were performed 1,3 , and $24 \mathrm{~h}$ after extubation and then on a daily basis up to day 4 . Chest $\mathrm{X}$-ray was obtained $2 \mathrm{~h}$ after surgery and then on a daily basis up to postoperative day 3 .

Self-assessment of dyspnea (i.e., respiratory disco mfort-shortness of breath) was performed by a visual analog scale (VAS) ranging from 0 (no dyspnea) to 10 (maximum dyspnea) (in Additional file 1: Figure S1).

\section{Endpoints}

The primary endpoint of the study was the overall incidence of patients developing clinically relevant hypoxemia (i.e., ratio of the partial pressure of arterial oxygen $\left(\mathrm{PaO}_{2}\right)$ to $\left.\mathrm{FiO}_{2}\left(\mathrm{PaO}_{2} / \mathrm{FiO}_{2}\right)<300 \mathrm{mmHg}\right)$ during the first four postoperative days.

Secondary outcomes were (i) the need for supplemental oxygen after study treatment discontinuation and within 7 days from randomization (i.e., a peripheral arterial oxygen saturation $\left(\mathrm{SpO}_{2}\right)<93 \%$ while breathing on room air); (ii) the occurrence of postoperative severe acute respiratory failure requiring ventilatory support; (iii) the degree of dyspnea over the course of the first four postoperative days; and (iv) the rate of pulmonary complications within 7 days after surgery.

In non-prespecified post hoc analyses, we also assessed (i) the overall incidence of patients developing mode rate-to-severe hypoxemia $\left(\mathrm{PaO}_{2} / \mathrm{FiO}_{2}<200 \mathrm{mmHg}\right)$ over the first $96 \mathrm{~h}$ after surgery; (ii) the cumulative incidence of clinically relevant hypercapnia (i.e., $\mathrm{PaCO}_{2}>45$ $\mathrm{mmHg}$ ) over the course of the first four postoperative days; (iii) $\mathrm{PaO}_{2} / \mathrm{FiO}_{2}$ and $\mathrm{PaCO}_{2}$ over the course of the first four postoperative days; (iv) the length of hospital stay; and (v) all-cause 30-day mortality. 
Postoperative severe acute respiratory failure requiring ventilatory support was defined as the presence of at least two of the followings: respiratory acidosis (arterial $\mathrm{pH} \leq 7.35$ with $\mathrm{PaCO}_{2}>45 \mathrm{mmHg}$ ); $\mathrm{SpO}_{2}<90 \%$ or $\mathrm{PaO}_{2}<60 \mathrm{mmHg}$ at an $\mathrm{FiO}_{2} \geq 0.5$; respiratory frequency $>35 / \mathrm{min}$; altered state of consciousness; and clinical signs of respiratory muscle fatigue [22]. Respiratory failure was initially treated with NIV, except when endotracheal intubation was required (i.e., cardiac arrest, loss of consciousness, psychomotor agitation, massive aspiration, persistent inability to remove respiratory secretions, heart rate $<50 / \mathrm{min}$ with loss of alertness, and severe hemodynamic instability without response to fluids and vasoactive drugs [22]). Patients with worsening blood gases and/or persistent tachypnea (respiratory rate $>35$ breaths $/ \mathrm{min}$ ) despite NIV received endotracheal intubation.

Postoperative pulmonary complications were defined as sub-lobar or lobar atelectasis, detected by the chest X-rays and scored using the radiological atelectasis score equal or greater than two [23]; nosocomial pneumonia (new-onset or progressive pulmonary infiltrates with at least two of the following: purulent respiratory secretions, temperature $>38^{\circ} \mathrm{C}$ or $<36^{\circ} \mathrm{C}$, and white blood cell count $>12,000$ / $\mathrm{mm}^{3}$ or $<4000 / \mathrm{mm}^{3}$ ) [24]. Non-pulmonary complications included new-onset cardiac arrhythmias, cardiac ischemia, hemodynamic instability requiring fluid or vasoactive resuscitation, hyperlactatemia, and metabolic acidosis.

The post hoc analyses on $\mathrm{PaCO}_{2}$ and hypercapnia development were conducted under the light of the most recent evidence suggesting a relevant effect of HFNC on $\mathrm{CO}_{2}$ washout in the upper airways [10-12, 25-27]. Results on these endpoints should be considered merely exploratory in nature.

\section{Statistical analysis}

Data on the rate of patients experiencing postoperative hypoxemia (defined as a $\mathrm{PaO}_{2} / \mathrm{FiO}_{2}$ ratio $<300$ $\mathrm{mmHg}$ within $96 \mathrm{~h}$ after surgery) during Venturi mask oxygen therapy after lung resection were lacking at the time of study design, but it was known that $50 \%$ of them show a $\mathrm{PaO}_{2} / \mathrm{FiO}_{2}<320 \mathrm{mmHg} 24 \mathrm{~h}$ after surgery while on low-flow oxygen [28]. Using a conservative approach, we hypothesized a $45 \%$-incidence of postoperative hypoxemia in the Venturi mask group, and we estimated that 45 patients per group were needed to detect a $60 \%$ relative reduction in the rate of the primary endpoint in the intervention group (estimated absolute risk in the intervention group, $18 \%$ ), with a type I error set at $5 \%$ and statistical power of $80 \%$. Given an attrition rate lower than $5 \%$, mostly due to protocol violations and crossover between treatments, we planned to enroll 94 patients.
The analysis was conducted on a "modified intention -to-treat" population that included all patients who underwent the allocated treatment for at least $6 \mathrm{~h}$.

Distribution normality was assessed with the Kolmogorov-Smirnov test. Continuous variables with normal distribution are reported as means ( \pm standard deviation), whilst those with non-normal distributions were expressed as medians (interquartile ranges).

Analysis on the primary efficacy criterion and for other categorical outcomes was performed with the $x^{2}$ test, or Fisher's exact test, as appropriate: Cochran-MantelHaenszel statistics are reported for all these results. For other relevant outcomes whose distribution was statistically different in the two groups at the univariate analysis, a logistic regression model was conducted: all variables with $p \leq 0.20$ at the univariate analysis were included. Kaplan-Meier curves were plotted to assess the time from enrollment to the primary endpoint or relevant secondary outcomes by means of the log-rank test; for secondary outcomes, Cox regression analysis was also conducted to confirm the independent effect of the treatment on the time from enrollment to occurrence of the endpoint: all variables with a log-rank $p \leq 0.20$ were included in the model. Two-way analysis of variance (ANOVA) for repeated measures with Bonferroni correction was used to determine the differences in $\mathrm{PaO}_{2} /$ $\mathrm{FiO}_{2}$ ratio, $\mathrm{PaCO}_{2}$, and dyspnea in the two groups. Comparisons between groups regarding these variables at each study timepoint were performed with the Student's $t$ test or Mann-Whitney test, as appropriate. Mean difference and 95\% confidence interval (95\% CI) are reported for most significant results.

Two-tail $p$ values $\leq 0.05$ were considered significant. Statistical analysis was performed with SPSS software package (SPSS Inc. Released 2009. PASW Statistics for Windows, Version 18.0. Chicago: SPSS Inc.).

\section{Results}

Between September 2015 and April 2018, of the 522 patients undergoing thoracic surgery for lung cancer, 99 patients were eligible for inclusion in the study and 96 underwent randomization. All enrolled patients were successfully extubated at the end of surgery and received the allocated treatment within $30 \mathrm{~min}$ after extubation.

One patient from the HFNC group was not included in the "modified intention-to-treat" population because, due to intolerance to the device, the patient received the allocated treatment for less than $6 \mathrm{~h}$. Data from $95 \mathrm{pa}$ tients (47 in the HFNC group and 48 in the Venturi mask group) were analyzed (Fig. 1).

Demographics, most relevant clinical characteristics, main comorbidities, preoperative arterial blood gases and respiratory function, and surgical procedures are reported in Table 1 and were well balanced in the two 


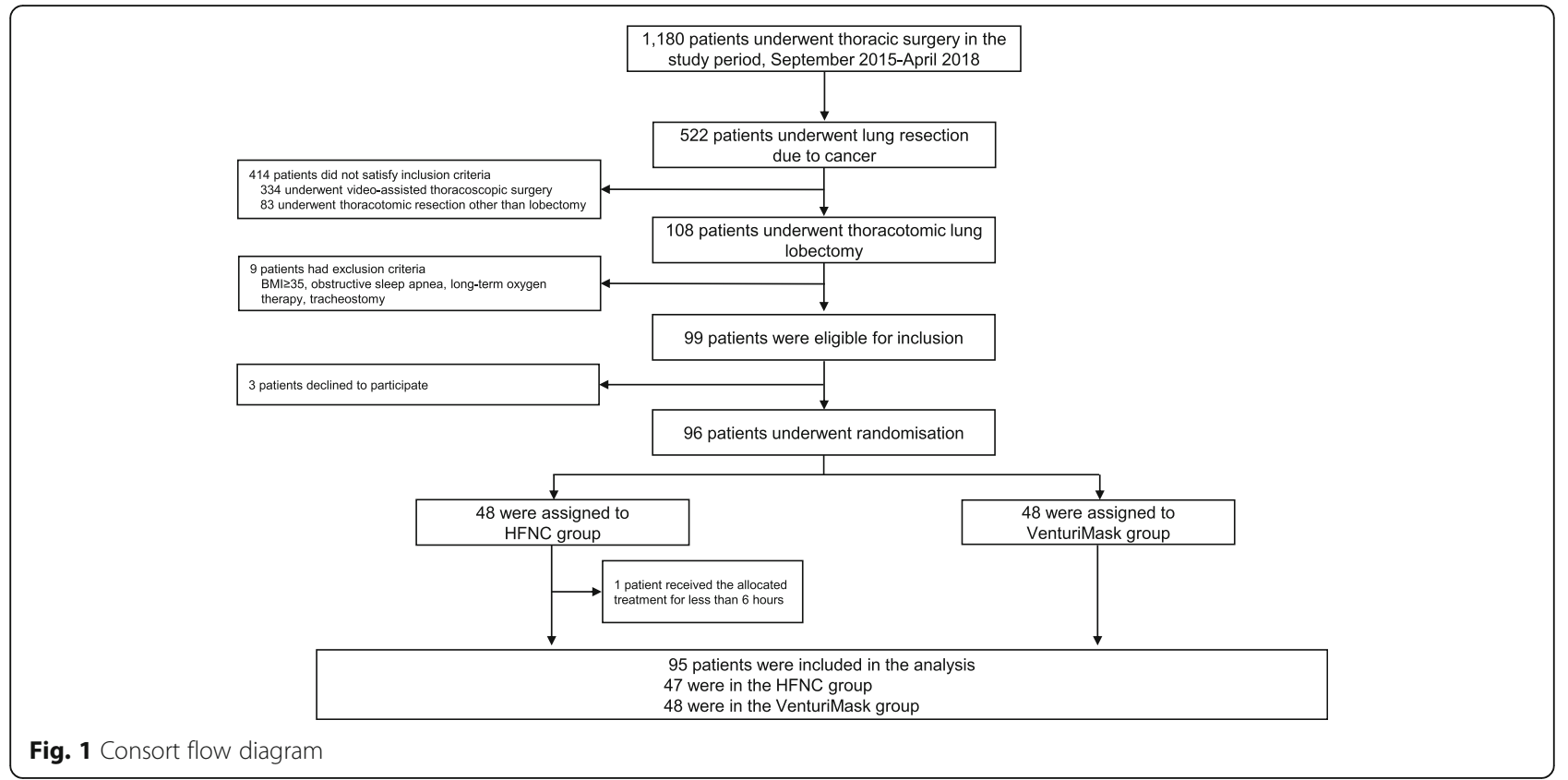

study groups. No patient had preoperative $\mathrm{PaCO}_{2}$ exceeding $45 \mathrm{mmHg}$. All patients had undergone thoracotomic lung lobar resection; mean duration of mechanical ventilation before extubation was $215 \min \pm 59$ in the HFNC group and $222 \pm 119$ in the Venturi mask group.

Mean $\mathrm{HFNC} \mathrm{FiO}_{2}$ at treatment start was $41 \% \pm 5$, with gas flow set at $50 \mathrm{l} / \mathrm{min}$ in all patients. In the Venturi mask group, mean $\mathrm{FiO}_{2}$ at treatment initiation was $39 \% \pm 4$ with a pure oxygen flow of $8 \pm 1 \mathrm{l} / \mathrm{min}$, which corresponded to a delivered nominal gas flow of $33 \pm 2 \mathrm{l} / \mathrm{min}$. Mean (CI 95\%) nominal $\mathrm{FiO}_{2}$ during the assigned treatment was $39 \%$ [29-31] in the HFNC group and 38\% [29, 30, 32] in the Venturi mask group $(p=0.23$, in Additional file 1: Figure S2).

Main results of the study are reported in Table 2.

Both in the HFNC and Venturi mask groups, 38 patients developed hypoxemia within $96 \mathrm{~h}$ after extubation ( $81 \%$ vs. $79 \%$, unadjusted odds ratio (OR) [95\% CI] for HFNC $1.11[0.41-3, p=0.84$ ) (Fig. 2). Similarly, the incidence of moderate-to-severe postoperative hypoxemia was not different between groups: $38 \%$ the in HFNC group vs. $33 \%$ in the Venturi mask group (unadjusted OR 1.24 [0.54-2.88], $p=0.67$ ) (in Additional file 1: Figure S3).

No inter-group differences were found regarding the main secondary outcomes that were analyzed (i.e., the incidence of acute respiratory failure requiring ventilatory support, pulmonary complications, number of patients requiring oxygen therapy after treatment discontinuation, and the dyspnea during the study (in Additional file 1: Figure S4)).

Over the course of the first $96 \mathrm{~h}$ after surgery, $\mathrm{PaO}_{2} /$ $\mathrm{FiO}_{2}$ was not different between groups $(p=0.92)$, although patients in the HFNC showed higher $\mathrm{PaO}_{2} /$ $\mathrm{FiO}_{2} 1 \mathrm{~h}$ after surgery: 347 vs. $304 \mathrm{mmHg}$, mean difference of $44 \mathrm{mmHg}$ [95\% CI 8-80] ( $p=0.017)$ (Fig. 3).

During the study, patients undergoing HFNC showed lower $\mathrm{PaCO}_{2}$, with a mean difference between groups of $2 \mathrm{mmHg}$ [95\% CI 0.5-3.4] (Fig. 3). Eight patients (17\%) in the HFNC group and $22(46 \%)$ in the Venturi mask group developed hypercapnia $\left(\mathrm{PaCO}_{2}>45 \mathrm{mmHg}\right)$ within $96 \mathrm{~h}$ after randomization $(p=0.004)$ : this finding remained significant after adjustment for possible confounders, with an OR of 0.18 [0.06-0.54], $p=0.002$ (univariate analysis reported in Additional file 2 KaplanMeier showed in Fig. 4). Importantly, $\mathrm{PaO}_{2}$ and $\mathrm{SpO}_{2}$ did not differ between groups in any of the analyzed study steps ( $p=0.49$ and $p=0.80$, respectively).

\section{Discussion}

In this randomized trial conducted in patients undergoing thoracotomic lung lobectomy, preemptive use of HFNC after extubation, as compared to Venturi mask oxygen therapy, did not result in lower incidence of postoperative hypoxemia nor had any effect on other prespecified secondary outcomes (incidence of postoperative respiratory complications and respiratory failure requiring ventilatory support, persistent need for oxygen therapy on postoperative day 2, postoperative dyspnea).

Because of anesthesia-induced pulmonary atelectasis, the development of surgical pneumothorax and the reduction in functional residual capacity generated by lung resection, hypoxemia represents a life-threatening complication and the leading cause of death in patients after thoracic surgery $[28,33]$. 
Table 1 Demographics and baseline clinical characteristics of enrolled patients

\begin{tabular}{|c|c|c|c|}
\hline Characteristic & & $\begin{array}{l}\text { HFNC } \\
(n=47)\end{array}$ & $\begin{array}{l}\text { Venturi mask } \\
\quad(n=48)\end{array}$ \\
\hline Age, years & & $66 \pm 10$ & $68 \pm 9$ \\
\hline Female sex & $n(\%)$ & $20(43)$ & $21(48)$ \\
\hline Height, $\mathrm{cm}$ & & $165 \pm 9$ & $166 \pm 9$ \\
\hline Weight, kg & & $72 \pm 14$ & $74 \pm 15$ \\
\hline Body mass index, $\mathrm{kg} / \mathrm{m}^{2}$ & & $26 \pm 4$ & $27 \pm 4$ \\
\hline American Society of Anesthesiologist physical status & $n(\%)$ & & \\
\hline 1 & & $1(2)$ & $2(4)$ \\
\hline$\|$ & & $33(70)$ & $31(75)$ \\
\hline III & & $13(28)$ & $15(21)$ \\
\hline Comorbidities & $n(\%)$ & & \\
\hline Induction therapy & & $6(13)$ & $6(13)$ \\
\hline History of cardiac failure & & $4(9)$ & $7(15)$ \\
\hline History of ischemic heart disease & & $5(11)$ & $11(23)$ \\
\hline Chronic obstructive pulmonary disease & & $25(53)$ & $32(67)$ \\
\hline Pulmonary infections in the preceding month & & $12(26)$ & $11(23)$ \\
\hline Active smoking & & $23(49)$ & $28(58)$ \\
\hline Diabetes & & $4(9)$ & $7(15)$ \\
\hline \multicolumn{4}{|l|}{ Preoperative respiratory function } \\
\hline $\mathrm{FEV}_{1}$, liters & & $2.2 \pm 0.7$ & $2.2 \pm 0.7$ \\
\hline Forced vital capacity, liters & & $3.2 \pm 0.9$ & $3.3 \pm 0.8$ \\
\hline Tiffenau index, \% & & $72 \pm 11$ & $70 \pm 10$ \\
\hline \multicolumn{4}{|l|}{ Preoperative arterial blood gases } \\
\hline $\mathrm{PaO}_{2}, \mathrm{mmHg}$ & & $85 \pm 10$ & $83 \pm 10$ \\
\hline $\mathrm{PaCO}_{2}, \mathrm{mmHg}$ & & $37 \pm 3$ & $37 \pm 3$ \\
\hline Patients with $\mathrm{PaCO}_{2} \geq 45 \mathrm{mmHg}$ & $n(\%)$ & 0 & 0 \\
\hline Side of surgery & $n(\%) 7$ & & \\
\hline Right & & $30(64)$ & $29(61)$ \\
\hline Left & & $17(36)$ & $19(39)$ \\
\hline Site of surgery & $n(\%)$ & & \\
\hline Upper lobe & & $24(51)$ & $28(59)$ \\
\hline Middle lobe & & $3(6)$ & $5(10)$ \\
\hline Lower lobe & & $20(42)$ & $15(31)$ \\
\hline \multicolumn{4}{|l|}{ Intraoperative tidal volume } \\
\hline \multicolumn{4}{|l|}{ During two-lung ventilation } \\
\hline $\mathrm{ml}$ & & $375(350-450)$ & $425(369-456)$ \\
\hline $\mathrm{ml} / \mathrm{kg}$ of predicted body weight & & $6.7(6.4-7)$ & $6.9(6.5-7.3)$ \\
\hline \multicolumn{4}{|l|}{ During one-lung ventilation } \\
\hline $\mathrm{ml}$ & & $300(263-325)$ & $313(250-350)$ \\
\hline $\mathrm{ml} / \mathrm{kg}$ of predicted body weight & & $5(4.9-5.2)$ & $5(4.9-5.2)$ \\
\hline Duration of mechanical ventilation, minutes & & $215 \pm 59$ & $222 \pm 119$ \\
\hline Duration of surgery, minutes & & $175 . \pm 66$ & $172 \pm 56$ \\
\hline Intraoperative blood loss, ml & & $50(0-200)$ & $90(0-163)$ \\
\hline Intraoperative crystalloids, ml & & $900(500-1500)$ & $650(500-1000)$ \\
\hline
\end{tabular}


Table 1 Demographics and baseline clinical characteristics of enrolled patients (Continued)

\begin{tabular}{|c|c|c|c|}
\hline Characteristic & & $\begin{array}{c}\text { HFNC } \\
(n=47)\end{array}$ & $\begin{array}{c}\text { Venturi mask } \\
\quad(n=48)\end{array}$ \\
\hline Post-surgical management* & $n(\%)$ & & \\
\hline Post-anesthesia care unit & & $42(89)$ & $39(81)$ \\
\hline Length of PACU stay, hours & & $6(5-7)$ & $6(5-7)$ \\
\hline Intensive care unit & & $5(11)$ & $9(19)$ \\
\hline Length of ICU stay, days & & $1(1-3)$ & $1(1-3)$ \\
\hline
\end{tabular}

Data are displayed as mean \pm standard deviation or median (interquartile range), if not otherwise specified

HFNC high-flow nasal cannula, $\mathrm{PaCO}_{2}$ arterial partial pressure of carbon dioxide, $\mathrm{PaO}_{2}$ arterial partial pressure of oxygen

IDefined on the basis of the GOLD definitions [41]

*The decision on whether the patient had to be transferred to the post-anesthesia or intensive care unit after extubation was taken by the attending anesthesiologist, who was aware of patient's inclusion in the trial but not of the randomization arm

Previous investigations in surgical and critically ill patients showed that HFNC may be of benefit after extubation. Favorable results on the preemptive use of HFNC, as compared to low-flow oxygen, have been reported in critically ill patients $[16,17]$, while the evidence appears conflicting in the postoperative period. After cardiac surgery, the use of HFNC does not yield improvement in oxygenation nor reduces the rate of atelectasis, but may be associated to a lower need for respiratory support escalation $[23,34]$ and may perform as well as noninvasive ventilation among patients at high risk for acute respiratory failure [19, 35]. After abdominal surgery, HFNC therapy does not reduce the incidence of hypoxemia or pulmonary complications in the postoperative period [36].

Differently, encouraging results emerge from trials comparing HFNC and low-flow oxygen in patients after thoracic surgery, who represent a specific population deemed at high risk for respiratory complications. When tested after thoracoscopic lung resection, HFNC was shown to improve oxygenation and decrease the rate of postoperative complications [37], with a possibly reduced postoperative length of stay [38].

If different studies addressed the differences between post-extubation HFNC and low-flow oxygen [39, 40], data on the clinical comparison between HFNC and Venturi mask are limited and confined to the setting of critical illness [20]. Thanks to the air entrainment effect, Venturi masks are capable to provide the patient with a nominal gas flow often above $30 \mathrm{l} / \mathrm{min}$, at predetermined $\mathrm{FiO}_{2}$. This allows delivery of mid-to-high gas flow with essentially stable $\mathrm{FiO}_{2}$ and makes the Venturi system an optimal, easy-to-use, "conventional strategy" for oxygen therapy in patients with high respiratory demand [32]. Accordingly, while the benefit on oxygenation by HFNC over low-flow oxygen is immediate and pronounced [12], it appears milder and delayed over Venturi mask [20]. This aspect contributes to explain why, despite improving weaning outcome in critical patients if compared to low-flow oxygen [17] (and performing as well as NIV in high-risk patients [16]), the clinical effect of HFNC might be limited when compared to Venturi mask, as shown in the present investigation. Importantly, whether any difference exists between HFNC and Venturi masks in terms of weaning outcome in the intensive care unit will be clarified by the results of a recent large randomized study (ClinicalTrials.gov NCT02107183).

The lack of a significant effect of HFNC on oxygenation and on the development of postoperative hypoxemia is not conflicting with what reported by Maggiore et al., who showed that HFNC could provide an improvement in oxygenation only after $24 \mathrm{~h}$ of treatment [20]. In that study, that was conducted in the critical care setting, patients were studied in the weaning from mechanical ventilation after acute respiratory failure and were hypoxemic at study entry, while our patients quickly recovered after surgery, possibly mitigating any delayed effect on oxygenation resulting from the technique used to deliver oxygen.

In our study, $\mathrm{PaCO}_{2}$ was lower in patients undergoing HFNC than in those receiving Venturi mask. Consistently, although this endpoint was exploratory in nature, we report a lower rate of postoperative hypercapnia in patients treated with HFNC. The benefit by HFNC on $\mathrm{CO}_{2}$ is a well-known effect of the treatment and results from washout of the upper airways and lower $\mathrm{CO}_{2}$ production by respiratory muscles [11, 12, 20, 29]. Moreover, more than half of our study population had chronic obstructive pulmonary disease (COPD): patients with chronic respiratory failure are prone to develop respiratory complications related to $\mathrm{CO}_{2}$ retention and benefit from HFNC also when in stable clinical conditions [25-27].

This study has limitations. First, it was conducted in a single center, and the generalizability of our results may be limited; however, patients were enrolled according to well-defined inclusion criteria, which should enhance the reproducibility of our findings. Second, it was not possible to blind staff and 
Table 2 Primary and secondary outcomes, according to the study group

\begin{tabular}{|c|c|c|c|c|}
\hline \multirow[t]{2}{*}{ Outcome } & \multicolumn{2}{|c|}{ Study group } & \multirow[t]{2}{*}{$p$ value } & \multirow{2}{*}{$\begin{array}{l}\text { Odds ratio or mear } \\
\text { difference ( } 95 \% \text { Cl) }\end{array}$} \\
\hline & $\begin{array}{l}\text { HFNC } \\
(n=47)\end{array}$ & $\begin{array}{l}\text { Venturi mask } \\
\quad(n=48)\end{array}$ & & \\
\hline
\end{tabular}

Primary outcome

Incidence of postoperative hypoxemia $\left(\mathrm{PaO}_{2} / \mathrm{FiO}_{2}<300 \mathrm{mmHg}\right)$
Unadjusted analysis
38
No. of patients
38
$\%$ of patients $(95 \% \mathrm{Cl})$
$81(69-93)$
$79(67-91)$

0.84

$1.11(0.41-3)$

Secondary outcomes

Need for supplemental oxygen after treatment discontinuation

Unadjusted analysis
No. of patients
24
21
$\%$ of patients $(95 \% \mathrm{Cl})$
$51(36-66)$
$44(29-58)$

Incidence of postoperative respiratory failure requiring ventilatory support*

Unadjusted analysis

$>0.999$

$0.67(0.11-4.18)$

No. of patients

2

$\%$ of patients $(95 \% \mathrm{Cl})$

$4(0-11)$

$6(0-13)$

Incidence of postoperative pulmonary complications

Unadjusted analysis

0.64

$1.29(0.51-3.25)$

No. of patients

13

$\%$ of patients $(95 \% \mathrm{Cl})$

$28(14-41)$

11

$23(11-35)$

Mean dyspnea during the first 4 postoperative days

ANOVA for repeated measures

$\begin{array}{lcc}\text { Mean } & 2.2 & 2.3 \\ 95 \% \mathrm{Cl} & 1.5-2.9 & 1.5-3\end{array}$

Other secondary outcomes

Incidence of moderate-to-severe postoperative hypoxemia $\left(\mathrm{PaO}_{2} / \mathrm{FiO}_{2}<200 \mathrm{mmHg}\right)$

Unadjusted analysis

No. of patients

$\%$ of patients $(95 \% \mathrm{Cl})$

$38(24-53)$

$33(20-47)$

Incidence of postoperative hypercapnia $\left(\mathrm{PaCO}_{2}>45 \mathrm{mmHg}\right.$ )

Unadjusted analysis

0.004

$0.24(0.09-0.63)$

No. of patients

8

22

$\%$ of patients $(95 \% \mathrm{Cl})$

$17(6-28)$

$46(31-60)$

Adjusted analysis

0.002

$0.18(0.06-0.54)$

Mean $\mathrm{PaO}_{2} / \mathrm{FiO}_{2}$

In the first four postoperative days

ANOVA for repeated measures

\section{Mean}

$95 \% \mathrm{Cl}$

During assigned treatments (two postoperative days)

ANOVA for repeated measures 
Table 2 Primary and secondary outcomes, according to the study group (Continued)

\begin{tabular}{|c|c|c|c|c|}
\hline \multirow[t]{2}{*}{ Outcome } & \multicolumn{2}{|c|}{ Study group } & \multirow[t]{2}{*}{$p$ value } & \multirow{2}{*}{$\begin{array}{l}\text { Odds ratio or mean } \\
\text { difference }(95 \% \mathrm{Cl})\end{array}$} \\
\hline & $\begin{array}{l}\text { HFNC } \\
(n=47)\end{array}$ & $\begin{array}{l}\text { Venturi mask } \\
\qquad(n=48)\end{array}$ & & \\
\hline \multicolumn{5}{|l|}{ Mean $\mathrm{PaCO}_{2}$} \\
\hline \multicolumn{5}{|l|}{ In the first four postoperative days } \\
\hline ANOVA for repeated measures & & & 0.015 & $-1.7(-3$ to -0.3$)$ \\
\hline Mean & 38.9 & 40.6 & & \\
\hline $95 \% \mathrm{Cl}$ & $38-39.8$ & $39.6-41.5$ & & \\
\hline \multicolumn{5}{|c|}{ During assigned treatments (two postoperative days) } \\
\hline \multicolumn{5}{|l|}{ ANOVA for repeated measures } \\
\hline Mean & 39.7 & 41.6 & 0.009 & $-2(-3.4$ to -0.5$)$ \\
\hline $95 \% \mathrm{Cl}$ & $38.7-40.6$ & $40.5-42.7$ & & \\
\hline \multicolumn{5}{|c|}{ Incidence of overall postoperative complications } \\
\hline Unadjusted analysis & & & 0.61 & $1.25(0.53-2.98)$ \\
\hline No. of patients & 16 & 14 & & \\
\hline$\%$ of patients $(95 \% \mathrm{Cl})$ & $34(20-48)$ & $29(16-43)$ & & \\
\hline \multicolumn{5}{|l|}{ Length of hospital stay, days } \\
\hline Unadjusted analysis & & & 0.83 & $-2(-8-4)$ \\
\hline Median & 6 & 6 & & \\
\hline Interquartile range & $5-7$ & $5-7$ & & \\
\hline \multicolumn{5}{|l|}{ 28-day mortality } \\
\hline Unadjusted analysis & & & $\mathrm{n} / \mathrm{a}$ & \\
\hline No. of patients & 0 & 0 & & \\
\hline
\end{tabular}

१The analysis was adjusted for age, history of clinically documented pulmonary infections in the month preceding surgery and preoperative $\mathrm{PaCO}_{2}$

*Four patients needed NIV (three patients in the Venturi mask group and one in the HFNC group) and two patients underwent endotracheal intubation (one in each group)

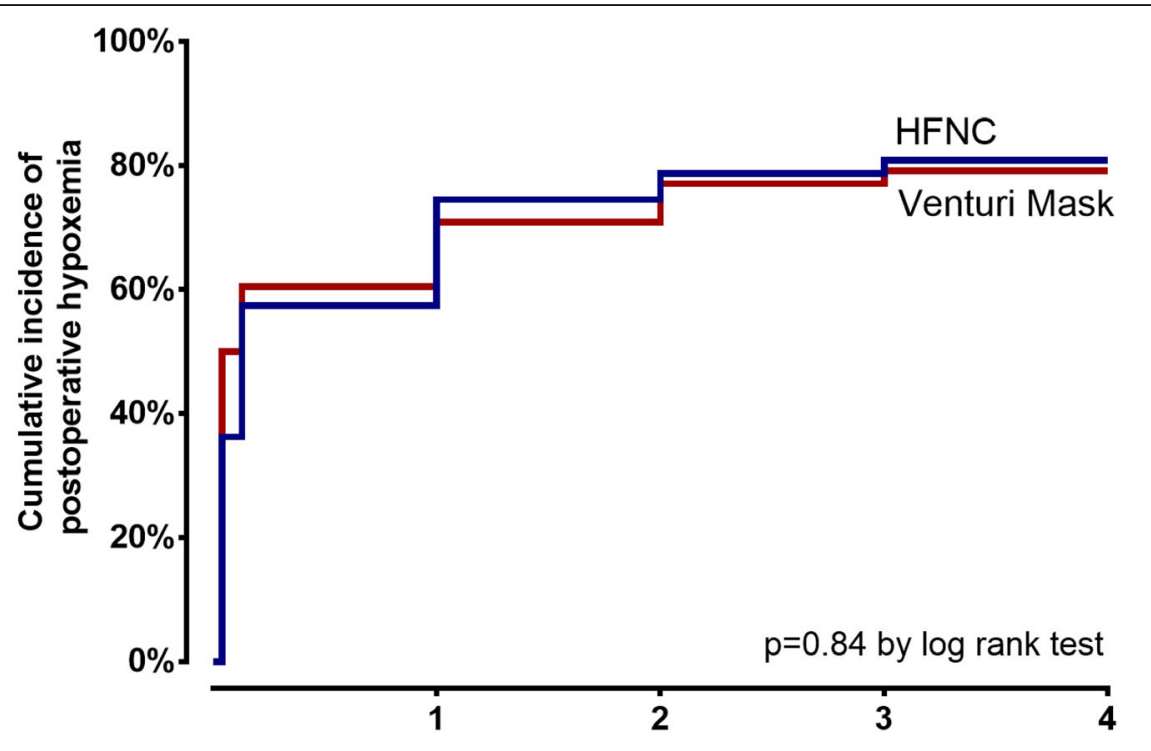

No. at risk

Days from randomization

$\begin{array}{lccccc}\text { HFNC } & 47 & 20 & 12 & 10 & 9 \\ \text { Venturi Mask } & 48 & 19 & 14 & 11 & 10\end{array}$

Fig. 2 Kaplan-Meier plots of the cumulative incidence of postoperative hypoxemia 

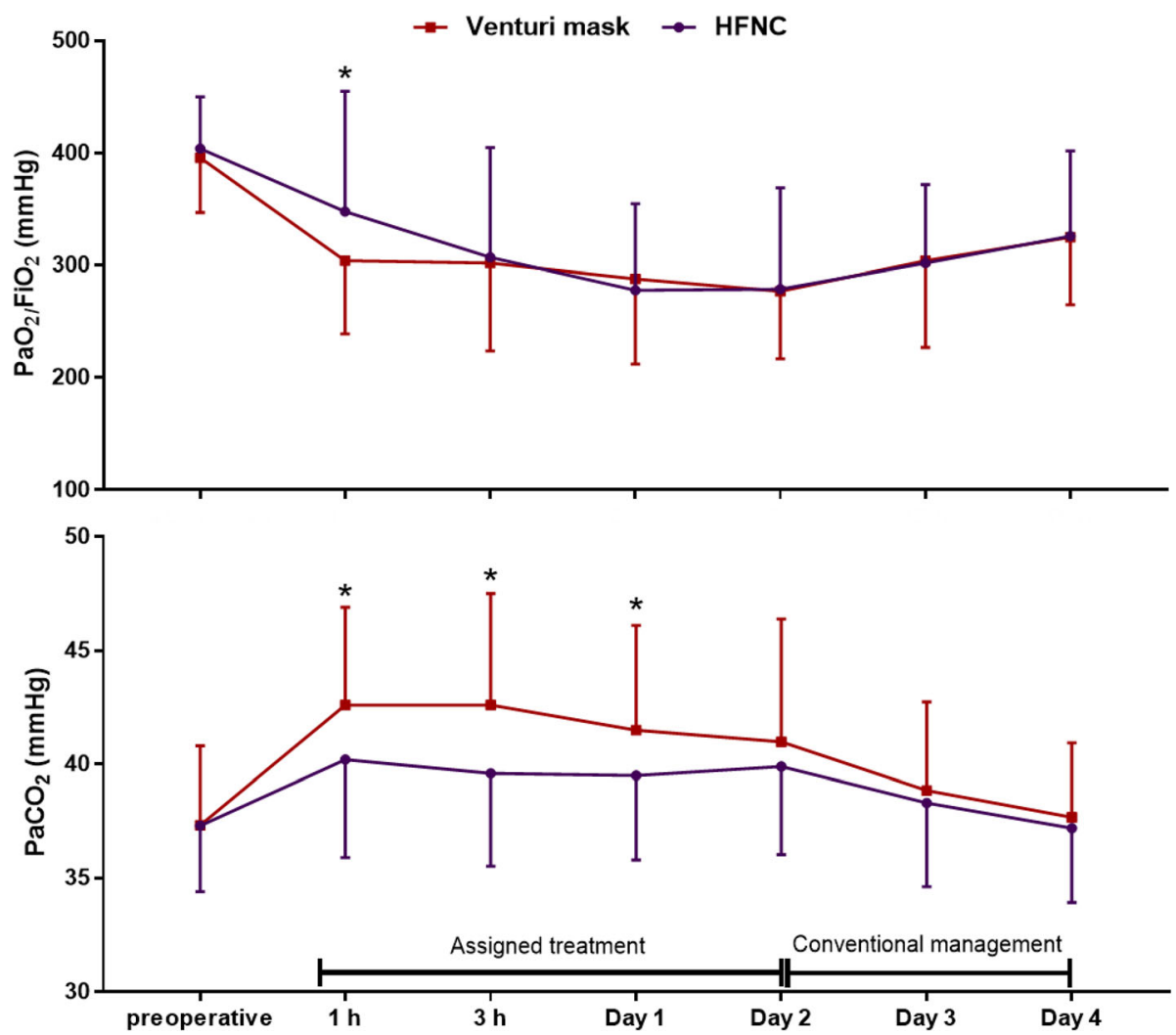

Fig. 3 Postoperative $\mathrm{PaO}_{2} / \mathrm{FiO}_{2}$ ratio and $\mathrm{PaCO}_{2}$ in the two study groups. Results are expressed as means and standard deviation. No differences were detected in the $\mathrm{PaO}_{2} / \mathrm{FiO}_{2}$ ratio (ANOVA $p=0.92$ ). Patients in the HFNC group showed lower $\mathrm{PaCO}_{2}$ over the entire course of the study (ANOVA $p=0.015$ ), with a mean difference between study treatments of $1.7 \mathrm{mmHg}[95 \% \mathrm{Cl} 0.3-3]$. This difference was particularly evident while the assigned treatments were administered, with a mean difference between groups of $2 \mathrm{mmHg}[95 \% \mathrm{Cl} 0.5-3.4]$ (ANOVA $p=0.009$ ). *Indicates $p$ $<0.05$ for the comparison between HFNC and Venturi mask at the single timepoint

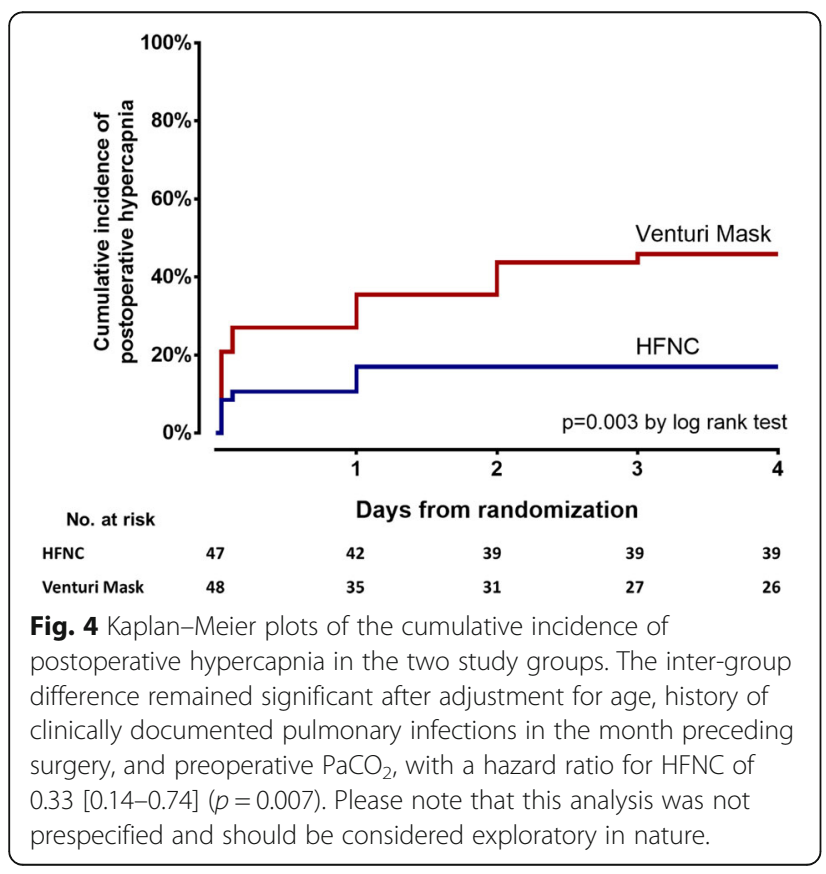

participants to treatment allocation: nonetheless, we took into account clinically objectifiable endpoints that were unlikely affected by assessors' unblinding. Third, we did not measure effectively delivered $\mathrm{FiO}_{2}$, as performed elsewhere [30]. As a result, the calculation of $\mathrm{PaO}_{2} / \mathrm{FiO}_{2}$ ratios could have been subject to errors [31]. Nevertheless, our approach is clinically reproducible, and the final mid-to-high flows produced by air entrainment during Venturi mask could have helped obtain parameters comparable with those obtained with HFNC. Fourth, we do not provide results about the respiratory rate, work-of-breathing or inspiratory effort, which were however not easy to obtain in a reliable fashion in the setting of a clinical trial. Finally, the analysis on the development of postoperative hypercapnia was conducted under the light of recent evidence indicating a clinical effect of HFNC on $\mathrm{CO}_{2}$ washout from upper airways [10-12, 25-27] and was not prespecified: these results, although confirmed after adjustment for possible confounders, should be seen as hypothesis-generating rather than conclusive. 


\section{Conclusions}

As compared with Venturi mask oxygen therapy in patients who undergo thoracotomic pulmonary lobectomy, preemptive HFNC early after extubation does not reduce the incidence of postoperative hypoxemia, does not limit the occurrence of postoperative pulmonary complications, and does not relieve dyspnea. Because recent data suggest that a major effect of HFNC is mediated by upper airways' washout, a possible benefit by preemptive HFNC on $\mathrm{CO}_{2}$ clearance may be of interest among patients undergoing thoracic surgery and warrants further adequately powered investigations.

\section{Additional files}

Additional file 1: Figure S1. Visual analog scale for the assessment of patient's dyspnea. Figure S2. Mean (standard deviation) $\mathrm{FiO}_{2}$ in the two study groups ( $p=0.23$ for the inter-group comparison). Figure S3. Kaplan-Meier plots of the cumulative incidence of moderate-to-severe postoperative hypoxemia, which was defined as a $\mathrm{PaO}_{2} / \mathrm{FiO}_{2}$ ratio lower than $200 \mathrm{mmHg}$. Figure S4. Postoperative dyspnea, as assessed by the visual analog scale, in the two study groups. No inter-group differences were detected (ANOVA $p=0.97$ ). A part of these results is displayed in Table 1. (PPTX $200 \mathrm{~kb}$ )

Additional file 2: Results of the univariate analysis on the factors associated with the development of postoperative hypercapnia. (DOCX $13 \mathrm{~kb}$ )

\section{Abbreviations}

BMI: Body mass index; COPD: Chronic obstructive pulmonary disease: HFNC: High-flow nasal cannula; PEEP: Positive end-expiratory pressure

\section{Acknowledgements}

none

\section{Funding}

Support was provided solely from institutional and/or departmental sources. This research did not receive any specific grant from funding agencies in the public, commercial, or not-for-profit sectors.

\section{Availability of data and materials}

The datasets used and/or analyzed during the current study are available from the corresponding author on reasonable request.

\section{Authors' contributions}

MAP, GB, MTC, and MA designed the study. DN, GMF, EM, EG, and SM enrolled the patients and recorded the data. LM and DLG analyzed the data. GB and MAP interpreted the results and drafted the manuscript. DLG, GDP, and MA critically revised the manuscript. All the authors revised and approved the final draft of the manuscript and agreed on submitting it to critical care.

\section{Ethics approval and consent to participate}

The study was approved by local Ethics Committee and written informed consent to data analysis was obtained by all studied patients

\section{Consent for publication}

Not applicable

\section{Competing interests}

MA has received payments for board participation from Maquet, Air Liquide, and Chiesi. MA and DLG disclose a research grant received by General Electrics Health Care. DLG has received payments for travel expenses by Maquet, Getinge, and Air Liquide and is supported by grants from SIAARTI/ Merck Sharp \& Dohme and ESICM (2017 Bernhard Dräger Award for Advanced Treatment of Acute Respiratory Failure). All other authors declare that they have no competing interests.

\section{Publisher's Note}

Springer Nature remains neutral with regard to jurisdictional claims in published maps and institutional affiliations.

\section{Author details}

'Dipartimento delle Scienze dell'Emergenza, Anestesiologiche e della Rianimazione, UOC di Anestesia, Rianimazione, Terapia Intensiva e Tossicologia Clinica, Fondazione Policlinico Universitario A. Gemelli IRCCS, Rome, Italy. ${ }^{2}$ Istituto di Anestesia e Rianimazione, Università Cattolica del Sacro Cuore, Rome, Italy. ${ }^{3}$ Dipartimento delle Scienze Cardiovascolari e Toraciche, UOC di Chirurgia Toracica, Fondazione Policlinico Universitario A. Gemelli, IRCCS, Rome, Italy. ${ }^{4}$ Istituto di Patologia Speciale Chirurgica, Università Cattolica del Sacro Cuore, Rome, Italy.

Received: 21 December 2018 Accepted: 17 February 2019 Published online: 28 February 2019

References

1. Memtsoudis SG, Besculides MC, Zellos L, Patil N, Rogers SO. Trends in lung surgery: United States 1988 to 2002. Chest. 2006;130:1462-70.

2. Boffa DJ, Allen MS, Grab JD, Gaissert HA, Harpole DH, Wright CD. Data from The Society of Thoracic Surgeons General Thoracic Surgery database: the surgical management of primary lung tumors. J Thorac Cardiovasc Surg. 2008:135:247-54.

3. Goodney PP, Lucas FL, Stukel TA, Birkmeyer JD. Surgeon specialty and operative mortality with lung resection. Ann Surg. 2005:241:179-84.

4. Jaber S, Antonelli M. Preventive or curative postoperative noninvasive ventilation after thoracic surgery: still a grey zone? Intensive Care Med. 2014:40:280-3

5. Perrin C, Jullien V, Vénissac N, Berthier F, Padovani B, Guillot F, et al. Prophylactic use of noninvasive ventilation in patients undergoing lung resectional surgery. Respir Med. 2007;101:1572-8.

6. Auriant I, Jallot A, Hervé P, Cerrina J, Le Roy LF, Fournier JL, et al. Noninvasive ventilation reduces mortality in acute respiratory failure following lung resection. Am J Respir Crit Care Med. 2001;164:1231-5.

7. Lorut C, Lefebvre A, Planquette B, Quinquis L, Clavier H, Santelmo N, et al. Early postoperative prophylactic noninvasive ventilation after major lung resection in COPD patients: a randomized controlled trial. Intensive Care Med. 2014:40:220-7.

8. Lefebvre A, Lorut C, Alifano M, Dermine H, Roche N, Gauzit R, et al. Noninvasive ventilation for acute respiratory failure after lung resection: an observational study. Intensive Care Med. 2009;35:663-70.

9. Hernández G, Roca O, Colinas L. High-flow nasal cannula support therapy: new insights and improving performance. Crit Care. 2017:21:62.

10. Mauri T, Alban L, Turrini C, Cambiaghi B, Carlesso E, Taccone P, et al. Optimum support by high-flow nasal cannula in acute hypoxemic respiratory failure: effects of increasing flow rates. Intensive Care Med. 2017;43:1453-63.

11. Möller W, Feng S, Domanski U, Franke K-J, Celik G, Bartenstein P, et al. Nasal high flow reduces dead space. J Appl Physiol. 2017;122:191-7.

12. Mauri T, Turrini C, Eronia N, Grasselli G, Volta CA, Bellani G, et al. Physiologic effects of high-flow nasal cannula in acute hypoxemic respiratory failure. Am J Respir Crit Care Med. 2017;195:1207-15.

13. Papazian L, Corley A, Hess D, Fraser JF, Frat J-P, Guitton C, et al. Use of highflow nasal cannula oxygenation in ICU adults: a narrative review. Intensive Care Med. Springer Berlin Heidelberg; 2016;42:1336-1349.

14. Mauri T, Galazzi A, Binda F, Masciopinto L, Corcione N, Carlesso E, et al. Impact of flow and temperature on patient comfort during respiratory support by high-flow nasal cannula. Crit Care. 2018;22:120.

15. Roca O, Riera J, Torres F, Masclans JR. High-flow oxygen therapy in acute respiratory failure. Respir Care. 2010;55:408-13.

16. Hernández G, Vaquero C, Colinas L, Cuena R, González P, Canabal A, et al. Effect of postextubation high-flow nasal cannula vs noninvasive ventilation on reintubation and postextubation respiratory failure in high-risk patients: a randomized clinical trial. JAMA. 2016:316:1565-74.

17. Hernández G, Vaquero C, González P, Subira C, Frutos-Vivar F, Rialp G, et al. Effect of postextubation high-flow nasal cannula vs conventional oxygen therapy on reintubation in low-risk patients: a randomized clinical trial. JAMA. 2016:315:1354-61.

18. Stéphan F, Bérard L, Rézaiguia-Delclaux S, Amaru P, BiPOP Study Group. Highflow nasal cannula therapy versus intermittent noninvasive ventilation in obese subjects after cardiothoracic surgery. Respir Care. 2017;respcare.05473. 
19. Stéphan F, Barrucand B, Petit P, Rézaiguia-Delclaux S, Médard A, Delannoy B, et al. High-flow nasal oxygen vs noninvasive positive airway pressure in hypoxemic patients after cardiothoracic surgery: a randomized clinical trial. JAMA. 2015;313:2331-9.

20. Maggiore SM, Idone FA, Vaschetto R, Festa R, Cataldo A, Antonicelli F, et al. Nasal high-flow versus Venturi mask oxygen therapy after extubation. Effects on oxygenation, comfort, and clinical outcome. Am J Respir Crit Care Med. 2014;190:282-8.

21. Acute Respiratory Distress Syndrome Network, Brower RG, Matthay MA, Morris A, Schoenfeld D, Thompson BT, et al. Ventilation with lower tidal volumes as compared with traditional tidal volumes for acute lung injury and the acute respiratory distress syndrome. N Engl J Med. 2000; 342:1301-8.

22. Ferrer M, Valencia M, Nicolas JM, Bernadich O, Badia JR, Torres A. Early noninvasive ventilation averts extubation failure in patients at risk: a randomized trial. Am J Respir Crit Care Med. 2006;173:164-70.

23. Corley A, Bull T, Spooner AJ, Barnett AG, Fraser JF. Direct extubation onto high-flow nasal cannulae post-cardiac surgery versus standard treatment in patients with a BMI $\geq 30$ : a randomised controlled trial. Intensive Care Med. 2015;41:887-94.

24. Bello G, Pennisi MA, Di Muzio F, De Pascale G, Montini L, Maviglia R, et al. Clinical impact of pulmonary sampling site in the diagnosis of ventilatorassociated pneumonia: a prospective study using bronchoscopic bronchoalveolar lavage. J Crit Care. 2016;33:151-7.

25. Fraser JF, Spooner AJ, Dunster KR, Anstey CM, Corley A. Nasal high flow oxygen therapy in patients with COPD reduces respiratory rate and tissue carbon dioxide while increasing tidal and end-expiratory lung volumes: a randomised crossover trial. Thorax. 2016;71:759-61.

26. Pisani L, Fasano L, Corcione N, Comellini V, Musti MA, Brandao M, et al. Change in pulmonary mechanics and the effect on breathing pattern of high flow oxygen therapy in stable hypercapnic COPD. Thorax. 2017; 72:373-5.

27. Sklar MC, Dres M, Rittayamai N, West B, Grieco DL, Telias I, et al. Highflow nasal oxygen versus noninvasive ventilation in adult patients with cystic fibrosis: a randomized crossover physiological study. Ann Intensive Care. 2018:8:85.

28. Licker MJ, Widikker I, Robert J, Frey J-G, Spiliopoulos A, Ellenberger C, et al. Operative mortality and respiratory complications after lung resection for cancer: impact of chronic obstructive pulmonary disease and time trends. Ann Thorac Surg. 2006;81:1830-7.

29. Möller W, Celik G, Feng S, Bartenstein P, Meyer G, Oliver E, et al. Nasal high flow clears anatomical dead space in upper airway models. J Appl Physiol. 2015;118:1525-32.

30. Frat J-P, Thille AW, Mercat A, Girault C, Ragot S, Perbet S, et al. High-flow oxygen through nasal cannula in acute hypoxemic respiratory failure. $\mathrm{N}$ Engl J Med. 2015;372:2185-96.

31. Sztrymf B, Messika J, Bertrand F, Hurel D, Leon R, Dreyfuss D, et al. Beneficial effects of humidified high flow nasal oxygen in critical care patients: a prospective pilot study. Intensive Care Med. 2011;37:1780-6.

32. Wong GL, Finnis ME. Use of venturi entrainment to deliver nasal high fow oxygen. Crit Care Shock. 2010;13:75-80.

33. Alam N, Park BJ, Wilton A, Seshan VE, Bains MS, Downey RJ, et al. Incidence and risk factors for lung injury after lung cancer resection. Ann Thorac Surg. 2007:84:1085-91 discussion 1091.

34. Parke R, McGuinness S, Dixon R, Jull A. Open-label, phase II study of routine high-flow nasal oxygen therapy in cardiac surgical patients. Br J Anaesth. 2013;111:925-31.

35. Maggiore SM, Battilana M, Serano L, Petrini F. Ventilatory support after extubation in critically ill patients. Lancet Respir Med. 2018;6:948-62.

36. Futier E, Paugam-Burtz C, Godet T, Khoy-Ear L, Rozencwajg S, Delay J-M, et al. Effect of early postextubation high-flow nasal cannula vs conventional oxygen therapy on hypoxaemia in patients after major abdominal surgery: a French multicentre randomised controlled trial (OPERA). Intensive Care Med. 2016:42:1888-98.

37. Yu Y, Qian X, Liu C, Zhu C. Effect of high-flow nasal cannula versus conventional oxygen therapy for patients with thoracoscopic lobectomy after extubation. Can Respir J. 2017;2017:7894631.

38. Ansari BM, Hogan MP, Collier TJ, Baddeley RA, Scarci M, Coonar AS, et al. A randomized controlled trial of high-flow nasal oxygen (Optiflow) as part of an enhanced recovery program after lung resection surgery. Ann Thorac Surg. 2016;101:459-64.
39. Wittenstein J, Ball L, Pelosi P, Gama de Abreu M. High-flow nasal cannula oxygen therapy in patients undergoing thoracic surgery. Curr Opin Anaesthesiol. 2019;32(1):44-49.

40. Brainard J, Scott BK, Sullivan BL, Fernandez-Bustamante A, Piccoli JR, Gebbink MG, et al. Heated humidified high-flow nasal cannula oxygen after thoracic surgery - a randomized prospective clinical pilot trial. J Crit Care. 2017; 40:225-8.

41. Vestbo J, Hurd SS, Agustí AG, Jones PW, Vogelmeier C, Anzueto A, et al. Global strategy for the diagnosis, management, and prevention of chronic obstructive pulmonary disease: GOLD executive summary. Am J Respir Crit Care Med. 2013;187:347-65.
Ready to submit your research? Choose BMC and benefit from:

- fast, convenient online submission

- thorough peer review by experienced researchers in your field

- rapid publication on acceptance

- support for research data, including large and complex data types

- gold Open Access which fosters wider collaboration and increased citations

- maximum visibility for your research: over $100 \mathrm{M}$ website views per year

At BMC, research is always in progress.

Learn more biomedcentral.com/submissions 